\title{
PENGEMBANGAN MEDIA PEMBELAJARAN BERBASIS KOMPUTER MODEL TUTORIAL INTERAKTIF UNTUK MENINGKATKAN MOTIVASI BELAJAR SISWA PADA MATERI POKOK RELASI DAN FUNGSI
}

\author{
Yudi Jepri Dianta ${ }^{1)}$, Ade Putri ${ }^{2)}$ \\ ${ }^{1)}$ SMP Negeri 5 Singingi Hilir, Riau \\ 2) SMA Mutiara Harapan, Riau \\ Email : diantayudi@gmail.com
}

\begin{abstract}
The background of this research is the lack of a valid, practical and effective ICT-based learning media to learn about relations and functions. This research uses the Research and Development $(R \& D)$ method. The development model used in this study is the Plomp instructional model which consists of five phases namely: (1) the initial investigation phase; (2) the design phase; (3) realization phase; (4) test, evaluation and revision phases; (5) implementation phase. The purpose of this study is to develop ICT-based learning media on the subject of relations and functions that are valid, practical and efficient. The subjects of the study were 33 students of VIII grade SMP Negeri 5 Singingi Hilir. The instruments used were validation questionnaire, student response questionnaire and learning motivation questionnaire. Questionnaire sheets were analyzed quantitatively and qualitatively. Based on the results of data analysis, the developed media are in a very valid category, practical to use on learning about relations and functions and effective to increase student learning motivation.
\end{abstract}

Keywords : ICT-based learning media, Research and development, Valid, Practical and effective.

\section{PENDAHULUAN}

Ilmu pengetahuan dan teknologi berkembang sangat pesat, sehingga dibutuhkan kompetensi yang baik agar dapat bersaing dan eksis dalam masa yang sangat kompetitif. Salah satu alternatif untuk dapat berkompetisi adalah membekali diri dengan matematika. Matematika sebagai ilmu dasar bagi perkembangan ilmu lainnya, sangat penting untuk dipelajari dan dipahami. Oleh karenanya Departemen Pendidikan Nasional (Depdiknas) mewajibkan seluruh peserta didik mempelajari matematika, mulai dari tingkat dasar hingga perguruan tinggi. Tujuannya adalah agar siswa terampil, berpikiran kritis, sistematis, logis, kreatif, dan berwawasan luas. Hal ini sangat memungkinkan sebagaimana tujuan pelajaran matematika di sekolah, yaitu agar siswa memiliki pengetahuan matematika, mampu menggunakan penalaran, terampil memecahkan masalah dan terampil dalam mengomunikasikan gagasan, juga memiliki sikap menghargai kegunaan matematika. (Depdiknas,2006,1)

Tujuan pembelajaran matematika ini penting, karena Guru harus mengerahkan segenap kemampuannya, agar pelajaran matematika dapat diterima dan ditanggapi dengan baik oleh siswa. Guru perlu melakukan persiapan yang matang sebelum melaksanakan proses pembelajaran, seperti mempelajari materi kembali, membuat alat peraga hingga menyiapkan media pembelajaran yang relevan. Sehingga para siswa dapat mencapai prestasi belajar yang diharapkan.

Perkembangan dunia komputer telah mencapai kemajuan yang sangat mengagumkan. Hampir semua bidang pekerjaan di dunia telah dikendalikan oleh komputer. Pekerjaan yang dahulu membutuhkan banyak tenaga manusia, sekarang telah tergantikan oleh mesin, yang kesemuanya itu dikendalikan oleh komputer. Saat ini pemanfaatan komputer telah meluas hingga menjangkau kepentingan pembelajaran, yaitu untuk membantu guru dalam meningkatkan mutu pembelajaran.

Namun pada kenyataannya tidak semua guru mampu memanfaatkan keunggulankeunggulan komputer untuk meningkatkan mutu pembelajaran. Menurut Yuhetty (dalam Rusman,2013), dimasa yang akan datang kurikulum sekolah akan berangsur-angsur menyesuaikan diri pada aspek IT, mulai dari perguruan tinggi dan sekolah menengah. Kesenjangan antara kebutuhan IT dalam 
pembelajaran dengan kurangnya kemampuan guru dalam memanfaatkan IT ini mendorong peneliti untuk melakukan suatu penelitian yang dapat menghasilkan produk pemanfaatan komputer dalam kepentingan pembelajaran.

Produk yang akan dihasilkan pada penelitian ini berupa media pembelajaran berbasis komputer. Menurut Priyanto (2009) media pembelajaran berbasis komputer adalah suatu media belajar berisi program (software) pembelajaran yang bersifat interaktif terdiri dari gabungan antara teks,gambar, grafis, sound, animasi, movie, audio dan video yang dibuat dengan program aplikasi komputer dan diakses/ditayangkan melalui bantuan komputer.

Pada penelitian ini peneliti ingin mengembangkan media pembelajaran berbasis komputer dengan model tutorial interaktif. Menurut Rustam (2013) program tutorial merupakan program pembelajaran yang digunakan dalam proses pembelajaran dengan menggunakan software berupa program komputer yang berisi materi pelajaran dan soal-soal latihan. Interaktif artinya siswa dapat berinteraksi langsung dengan media yang dibuat, sehingga media pembelajaran yang dibuat nantinya dapat digunakan walaupun tanpa bimbingan guru. Hal ini memungkinkan siswa melakukan pembelajaran secara mandiri, sehingga pelajar menjadi lebih kreatif dan mau berusaha sendiri untuk memahami pelajaran.

Media pembelajaran yang dikembangkan diharapkan dapat meningkatkan motivasi belajar siswa. Menurut Resiani (2015) Keberadaan multimedia pembelajaran berbasis komputer, akan membuat proses pembelajaran menjadi lebih menarik, salah satunyadapat dilihat dari segi tampilan media yang dikombinasikan dengan beberapa foto ataupun animasi. Kombinasi ini dapat menimbulkan tampilan fisik yang menarik. Kemenarikan tampilan fisik sangat mempengaruhi proses pembelajaran, semakin menarik tampilan multimedia maka siswa semakin termotivasi untuk mengikuti pelajaran. Keindahan, kemenarikan dan adanya interaktivitas dalam suatu media pembelajaran merupakan sarana agar peserta didik tidak jenuh dalam mengikuti pelajaran dan efek terbesar yang diharapkan adalah meningkatnya motivasi belajar peserta didik (Fanny, 2013).

Pada penelitian ini, peneliti membatasi pengembangan media dibuat pada materi relasi dan fungsi kelas VIII SMP. Berdasarkan anilisis kebutuhan materi relasi dan fungsi merupakan salah satu materi yang menarik untuk dikembangakan dalam media karena karakteristik materi relasi dan fungsi yang cenderung abstrak. Ini menjadi tantangan tersendiri bagi peneliti untuk membuat suatu media yang dapat menyajikan materi relasi dan fungsi ini kedalam bentuk yang lebih konkret.

Dalam pembuatan media pembelajaran berbasis komputer model tutorial interaktif ini peneliti menggunakan beberapa program komputer yang telah tersedia seperti Microsoft Office Power Point 2007, Microsoft Office Excel 2010, Microsoft Word 2010, Autorun Interpraise, Adobe Photoshop CS 5, dan Snapa Shot. Program-program ini dapat dijadikan sebagai alat untuk membuat media yang menarik bagi kebutuhan media pembelajaran matematika. Dengan menggunakan fitur-fitur yang terdapat pada program komputer, kesulitan-kesulitan pada materi relasi dan fungsi dapat dikurangi. Pemahaman konsep diawali dengan wacana kontekstual, yang dimaksudkan untuk memotivasi siswa belajar relasi dan fungsi. Dimaksudkan juga bahwa relasi dan fungsi sangat dekat dengan kehidupan sehari-hari dan bermanfaat bagi yang ingin mengembangkan diri untuk memperdalam pengetahuan mengenai relasi dan fungsi. Kemudian materi-materi dijelaskan secara jelas, menarik dan terperinci, agar siswa dapat mempelajarinya secara mandiri di rumah.

Berdasarkan uraian di atas maka bertujuan untuk menghasilkan media pembelajaran berbasis komputer model tutorial interaktif yang valid, praktis dan efektif untuk meningkatkan motivasi belajar siswa pada materi relasi dan fungsi.

\section{METODE}

Metode penelitian yang digunakan pada pengembangan perangkat pembelajaran ini mengacu pada pengembangan instruksional Plomp yang terdiri atas lima tahap (fase) yaitu : (1) fase investigasi awal; (2) fase disain; (3) fase realisasi; (4) fase tes, evaluasi, dan revisi; 
(5) fase implementasi. Penelitian ini dilaksanakan di SMPN 5 Singingi Hilir. Dengan subjek uji coba adalah siswa Kelas VIII SMPN 5 Singingi Hilir sebanyak 33 orang. 5 orang siswa untuk uji coba kelompok kecil dan 28 siswa untuk uji coba kelompok besar. Instrumen pengumpulan data terdiri dari lembar validasi media pembelajaran berbasis komputer model tutorial interaktif pada materi relasi fungsi ,angket respon siswa, angket keterlaksanaan penggunaan media dan angket motivasi belajar siswa

Hasil penelitian setiap fase pengembangan yang telah dilaksanakan adalah sebagai berikut :

1. Fase Investigasi Awal

Pada fase ini, peneliti menganalisis kesesuaian isi materi relasi dan fungsi dengan SK dan KD sebagai acuan dalam penyusunan materi ajar di setiap pertemuan. berdasarkan analisis ini peneliti membagi media yang dikembangkan kedalam empat submateri yaitu : (1)Relasi, (2)Fungsi, (3) Nilai Fungsi dan (4) Sketsa grafik fungsi aljabar sederhana. Setiap Submateri disusun untuk satu pertemuan.

\section{Fase Desain}

Pada fase ini peneliti merancang flowchart dan struktur media yang akan di kembangkan. Berdasarkan struktur program yang telah dibuat peneliti menvuat rancangan awal tampilan media untuk setiapa halaman. Desain awal setiap halaman adalah sebagai berikut :

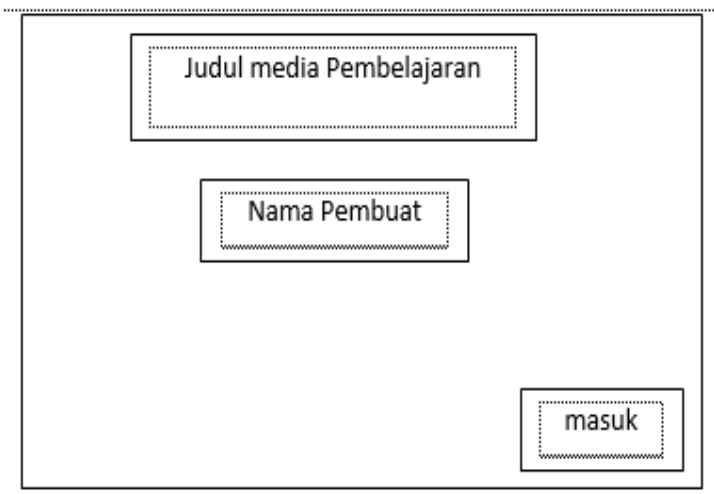

Gambar 1. Rancangan Halaman Judul

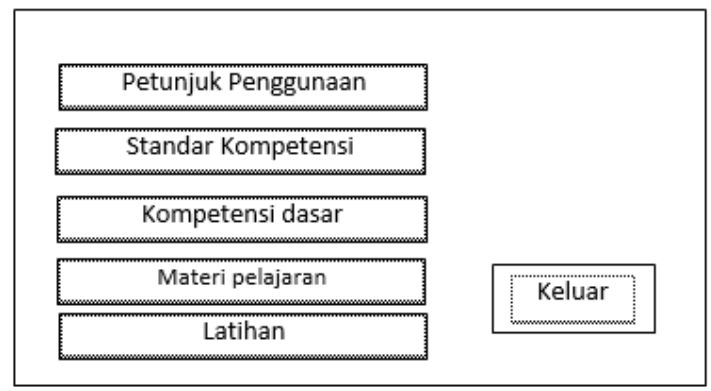

Gambar 2. Rancangan Menu Utama

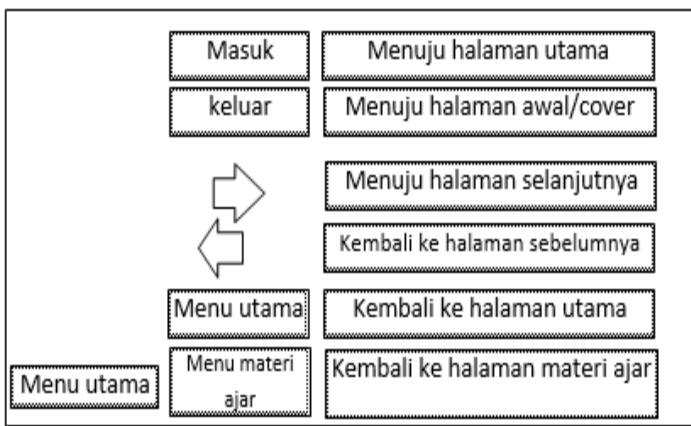

Gambar 3. Rancangan Halaman Petunjuk

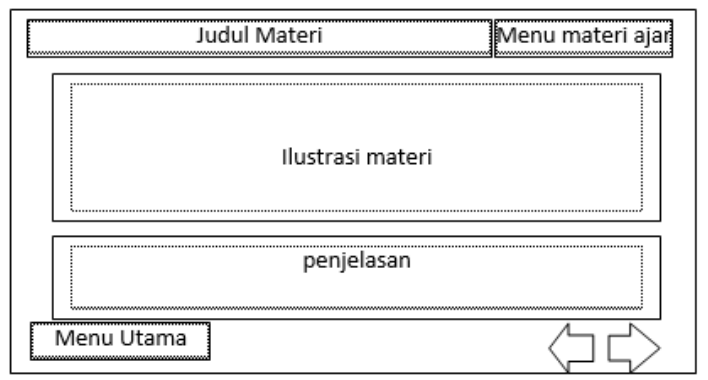

Gambar 4. Rancangan Halaman Materi ajar

\section{Fase Realisasi}

Pada fase realisasi ini peneliti membuat media pembelajaran sesuai dengan rancangan struktur program yang telah dibuat pada tahap desain. Setelah melalui tahapan revisi, tampilan program yang dibuat adalah sebagai berikut :

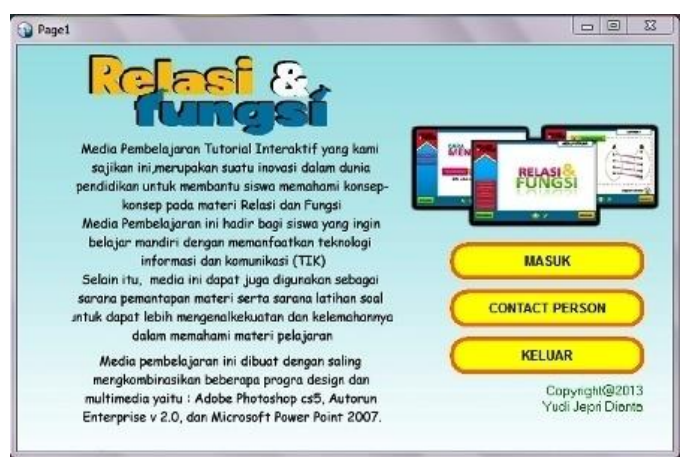

Gambar 5. Realisasi Halaman Judul 
Halaman judul dibuat menggunakan program Autorun enterprise $v$ 2.0. Pda Halaman judul terdpat deskripsi singkat tentang media pembelajaran dan 3 pilihan menu yaitu masuk, untuk memulai program,contact person untuk menampilkan kontak peneliti dan keluar untuk menutup program.

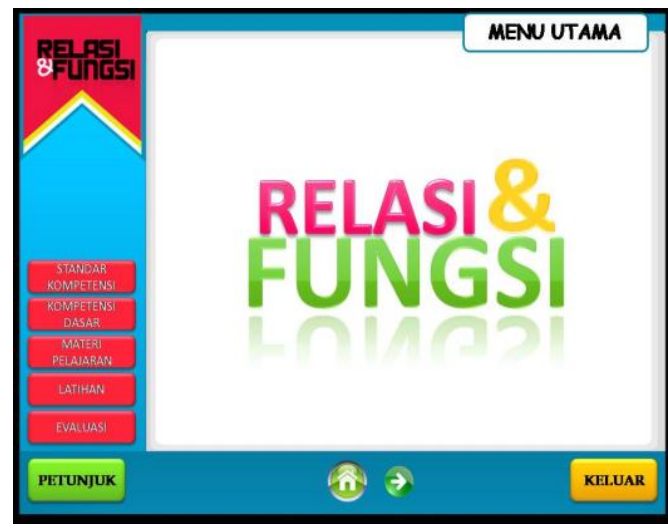

Gambar 6. Realisasi Halaman menu utama

Halaman menu utama dibuat menggunakan program microsoft office power point 2007. Disebelah kiri halaman menu utama terdapat pilihan menu yaitu : standar kompetensi, kompetensi dasar, materi ajar dan latihan. Semua menu telah diberikan link ke halamannya masing-masing, sehingga pengguna cukup mengklik pada salah satu pilihan menu tersebut untuk menampilkan halaman yang diinginkan. Pada halaman menu utama peneliti juga meletakkan tombol navigasi untuk melihat petunjuk penggunaan media dan tombil navigasi untuk menutup media.

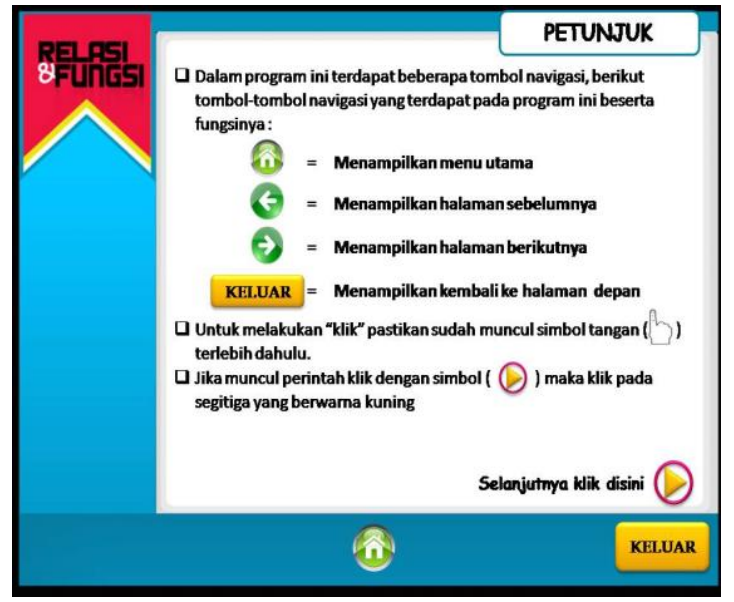

Gambar 7. Realisasi Halaman Petunjuk
Halaman petunjuk penggunaan dibuat menggunakan program microsoft office power point 2007. Halaman petunjuk penggunaan berisi petunjuk kegunaan tombol-tombol navigasi yang terdapat disetiap halaman dan petunjuk singkat tentang cara penggunaan media.

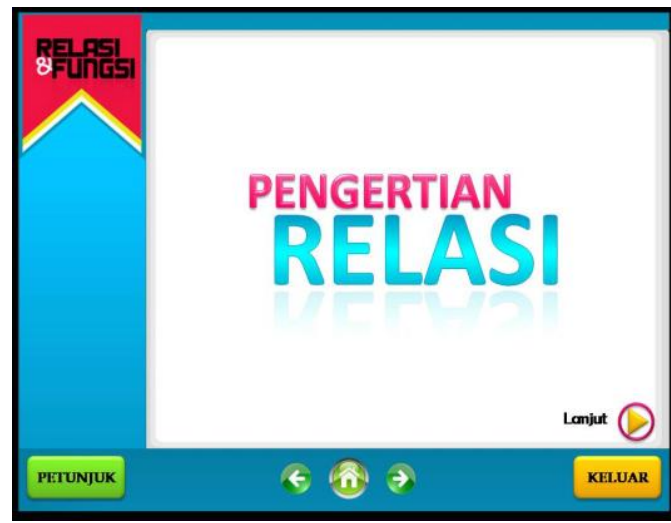

Gambar 8. Realisasi Halaman Materi Ajar

Halaman materi ajar berisi penjelasan untuk setiap materi yang disertai dengan animasi dan gambar ilustrasi yang dapat membantu siswa dalam memahami materi.

4. Fase Tes, Evaluasi dan Revisi

Pada fase ini peneliti melakukan uji validitas terhadap prototipe awal media yang telah dibuat. Data Fase berdasarkan rancangan awal pada fase desain. Hasil validasi kemudian dianalisis kemudian dijadikan sebagai bahan perbaikan dan penyempurnaan prototipe awal media.

\section{Fase Implementasi}

Pada fase ini, media pembelajaran yang sudah valid dan melalui tahap revisi di uji cobakan untuk melihat keefektifan media dalam meningkatkan motivasi belajar siswa.

Teknik analisis data yang digunakan pada penelitian ini adalah :

1. Analisis Kevalidan

Penilaian validator menggunakan skala 1 sampai 4 sebagai berikut.

Tabel 1. Skala Penilaian Validator

\begin{tabular}{cc}
\hline Skala Penilaian & Kriteria \\
\hline 4 & Sangat Baik \\
3 & Baik \\
2 & Kurang \\
1 & Sangat Kurang \\
\hline
\end{tabular}

Sumber : Sudaryono, dkk. 2013 
Kemudian hasil angket validasi dianalisis dengan beberapa langkah yaitu sebagai berikut.

a. Menghitung rata-rata perolehan skor masing-masing aspek dengan rumus:

$$
\bar{x}=\frac{\sum x}{n}
$$

Keterangan :

$$
\begin{aligned}
\bar{x}= & \text { Rata-rata perolehan skor } \\
\sum x= & \text { Banyaknya skor yang } \\
& \text { diperoleh tiap aspek } \\
n= & \text { banyak validator }
\end{aligned}
$$

b. Mendeskripsikan rata-rata skor tiap aspek yang diperoleh menjadi data kualitatif menurut kriteria penilaian.

Tabel 2. Rumus Konversi Skor Kualitatif

\begin{tabular}{cc}
\hline Rentang Skor & Kriteria \\
\hline $\bar{x}>M i+1,8 S b i$ & Sangat \\
& valid \\
$M i+0,6 S b i<\bar{x} \leq M i+1,8 S b i$ & Valid \\
$M i-0,6 S b i<\bar{x} \leq M i+0,6 S b i$ & Kurang \\
& valid \\
$\bar{x} \leq M i-0,6 S b i$ & Tidak valid \\
\hline
\end{tabular}

Sumber : Widoyoko, 2012

2. Analisis Kepraktisan

Kuesioner peserta didik bertujuan untuk mengetahui bagaimana respon peserta didik terhadap media yang telah dikembangkan. Berikut rentang skor yang digunakan menurut Widoyoko (2012).

Tabel 3. Konversi Skor Angket Respon Peserta Didik

\begin{tabular}{cc}
\hline Rentang Skor & Kriteria \\
\hline $\bar{x}>3,4$ & Sangat praktis \\
$2,8<\bar{x} \leq 3,4$ & Praktis \\
$2,2<\bar{x} \leq 2,8$ & Kurang praktis \\
$\bar{x} \leq 2,2$ & Sangat kurang praktis \\
\hline
\end{tabular}

Pada penelitian ini, media pembelajaran dinyatakan praktis apabila memenuhi kriteria minimal "Praktis" dengan rentang skor 2,8< $\bar{x} \leq 3,4$ dari penilaian oleh respon peserta didik.

\section{Analisis Keefektifan}

Analisis angket motivasi dilakukan untuk mengetahui kriteria motivasi peserta didik sesudah penggunaan media. Berikut kriteria motivasi belajar matematika menurut Widoyoko (2012).
Tabel 4. Kriteria Motivasi Belajar

\begin{tabular}{cc}
\hline Kategori & Kriteria \\
\hline$X>85$ & Sangat Baik \\
$70<X \leq 85$ & Baik \\
$55<X \leq 70$ & Cukup \\
$40<X \leq 55$ & Kurang \\
$X \leq 40$ & Sangat Kurang \\
\hline
\end{tabular}

\section{HASIL DAN PEMBAHASAN}

1. Validitas Media Pembelajaran Berbasis Komputer Model Tutorial Interaktif pada Pokok Bahasan Relasi an Fungsi Kelas VIII SMP.

Proses validasi terhadap media dilakukan pada tiga aspek yaitu aspek materi, aspek konstruksi media (IT) dan aspek bahasa. Yang bertindak selaku validator disini adalah 4 orang pakar yang memahami tentang

\begin{tabular}{|c|c|c|c|c|}
\hline Aspek & Item & $\sum$ & $\sum x$ & $\bar{x}$ \\
\hline \multirow{8}{*}{$\begin{array}{l}\text { Konstruksi } \\
\text { Materi }\end{array}$} & A & 15 & \multirow{8}{*}{121} & \multirow{8}{*}{3,781} \\
\hline & B & 15 & & \\
\hline & $\bar{C}$ & 16 & & \\
\hline & D & 15 & & \\
\hline & $\mathrm{E}$ & 14 & & \\
\hline & $\mathrm{f}$ & 16 & & \\
\hline & $\mathrm{g}$ & 15 & & \\
\hline & $\mathrm{h}$ & 15 & & \\
\hline
\end{tabular}
pembelajaran matematika. Hasil validasi media pembelajaran yang dikembangkan dapat dilihat pada tabel dibawah ini.

\begin{tabular}{|c|c|c|c|c|}
\hline Aspek & item & $\sum$ & $\sum x$ & $\overline{\boldsymbol{x}}$ \\
\hline Konstruksi & $\mathrm{a}$ & 12 & \multirow{7}{*}{97} & \multirow{7}{*}{3,464} \\
\hline \multirow[t]{6}{*}{ Media } & $\mathrm{b}$ & 14 & & \\
\hline & $\mathrm{c}$ & 12 & & \\
\hline & $\mathrm{d}$ & 15 & & \\
\hline & $\mathrm{e}$ & 15 & & \\
\hline & $\mathrm{f}$ & 16 & & \\
\hline & $\mathrm{g}$ & 13 & & \\
\hline
\end{tabular}

Tabel 5. Hasil Validasi Materi Oleh Validator

\begin{tabular}{|c|c|c|c|c|}
\hline Aspek & item & $\sum$ & $\sum x$ & $\bar{x}$ \\
\hline Konstruksi & $\mathrm{a}$ & 14 & \multirow[b]{2}{*}{29} & \multirow[b]{2}{*}{3,625} \\
\hline Bahasa & $\mathrm{b}$ & 15 & & \\
\hline
\end{tabular}

Tabel 6. Hasil Validasi Media Oleh Validator

Tabel 7. Hasil Validasi Bahasa Oleh validator 
Berdasarkan analisis data hasil validasi oleh validator terhadap media pembelajaran berbasis komputer model tutorial interaktif pada pokok bahasan relasi dan fungsi, diperoleh bahwa media pembelajaran berbasis komputer model tutorial interaktif pada pokok bahasan relasi dan fungsi sudah berada pada tingkat sangat valid untuk keseluruhan aspek, baik aspek materi, asek konstruksi media (IT) maupun aspek bahasa.

2. Praktikalitas Media Pembelajaran Berbasis Komputer Model Tutorial Interaktif pada Pkok Bahasan Relasi dan Fungsi Kelas VIII SMP.

Tingkat praktikalitas media pembelajaran berbasis komputer model tutorial interaktif pada pokok bahasan relasi dan fungsi kelas VIII SMP ini diperoleh dari hasil angket respon dan keterlaksanaan. Adapun hasil uji coba kelompok besar sebagai berikut:

Tabel 8. Hasil Uji Coba Kelompok Besar

\begin{tabular}{cc}
\hline Aspek & Rata-rata \\
\hline Tampilan & 3,47 \\
Materi & 3,13 \\
Program & 3,25 \\
\hline $\bar{x}$ & 3,28 \\
\hline
\end{tabular}

Berdasarkan Tabel 8 menunjukkan bahwa uji coba produk media pembelajaran berbasis komputer termasuk kategori "praktis". Para responden menyatakan bahwa mereka dapat mengoperasikan media pembelajaran dengan baik. Uraian materi relasi dan fungsi pada media pembelajaran mudah dipelajari, tampilan dan keterangan menu sangat jelas, tampilan media pembelajaran sangat menarik dan bahasa yang digunakan mudah dimengerti.

3. Keefektifan Media Pembelajaran Berbasis Komputer Model Tutorial Interaktif pada Pokok Bahasan Relasi dan Fungsi Kelas VIII SMP

Berdasarkan hasil uji $\mathrm{t}$ data angket motivasi belajar peserta didik sesudah penggunaan media pembelajaran menggunakan One Sample t-Test dengan SPSS 16.0 dengan taraf signifikansi adalah 0.000, maka $p<\propto=0,05$ diperoleh $\mathrm{t}$ hitung $=$ $42,744>\mathrm{t}_{\text {tabel }}=1,713$, sehingga $\mathrm{H}_{0}$ ditolak. Dengan demikian dapat disimpulkan bahwa media pembelajaran matematika berbasis komputer model tutorial interaktif yang dikembangkan cukup efektif ditinjau dari aspek motivasi belajar siswa. Hasil ini sejalan dengan penelitian yang dilakukan Karuniakhalida, dkk (2019) yang pada materi program linier.

\section{SIMPULAN}

Berdasarkan penelitian yang telah dilaksanakan, telah dihasilkan media pembelajaran berbasis komputer model tutorial interaktif pada materi relasi dan fungsi yang valid dan praktis untuk digunakan dalam pembelajaran serta efisien untuk meningkatkan motivasi belajar siswa. Media yang dikembangkan berada pada kategori "sangat valid" ditinjau dari aspek validitas dan "praktis" ditinjau dari aspek praktikalitas serta efektif ditinjau dari pencapaian tujuan penelitian

\section{DAFTAR PUSTAKA}

Arikunto, S. (2004). Evaluasi Program Pendidikan. Jakarta: Bumi Aksara.

Depdiknas. (2006). Kurikulum SMA. Jakarta : Depdiknas.

Widoyoko, E.P. (2012). Teknik penyusunan instrumen penelitian. Yogyakarta: Pustaka Pelajar

Fanny, A.M., \& Suardiman, S.P. (2013). Pengembangan Multimedia Interaktif untuk Mata Pelajaran Ilmu Pengetahuan Sosial (IPS) Sekolah Dasar Kelas V. Jurnal Prima Edukasia, 1(1), 1-9

Priyanto, D. (2009). Pengembangan Multimedia Pembelajaran Berbasis Komputer. Insania, 14(1), 92-110.

Karuniakhalida, P., Maimunah, \& Murni, A. (2019). Development of ICT-Based Mathematical Media on Linear Program Materials to Improve Motivation Learning Students. Journal of Educational Sciences 3(2), 195204. http://dx.doi.org/10.31258/jes.3.2. p.195-204 
PRINSIP Pendidikan Matematika

Volume 2, Nomor 1, November 2019

Resiani, N.K., Agung, A.A.G., Jampel, I.N. (2015). Pengembangan Multimedia Pembelajaran Interaktif pada Mata Pelajaran IPS Siswa Kelas VII Semester Genap di SMP Negeri7 Singaraja Tahun Ajaran 2014/2015. e-Journal Edutech Universitas Pendidikan Ganesha Jurusan Teknologi Pendidikan, 3(1).

Ravikoh. (2012). Pengembangan media pembelajaran berbasis komputer model tutorial interktif pada pokok bahsan dimensi tiga kelas X SMA. Pekanbaru: Pasca Sarjana UR (Tesis Tidak Diterbitkan)
Rusman.(2013). Model-Model Pembelajaran: Mengembangkan Profesionalisme Guru, Jakarta : Rajawali Press

Sudaryono, G.M., \& Rahayu, W. (2013). Pengembangan Instrumen Penelitian Pendidikan. Yogyakarta: Graha Ilmu.

Sudiyono, A.(2009). Pengantar Statistik Pendidikan. Jakarta: Rajawali Press 